\title{
OTR2 BioForm: o CRF eletrônico de Bio-Manguinhos
}

Elizabeth Maciel de Albuquerque ${ }^{1}$, Suelen Renata Estácio Marques ${ }^{1}$, André Queiroz da Silveira ${ }^{1}$, Kellen Cristina de Almeida Nery ${ }^{1}$, Marcelo Corrêa de Castro ${ }^{1}$, Sergio Fernando Oliveira Theodoro dos Santos ${ }^{2}$, Maria de Lourdes Sousa Maia ${ }^{1}$

1 Instituto de Tecnologia em Imunobiológicos, Bio-Manguinhos, Fiocruz, Rio de Janeiro, RJ

2 Serviço Federal de Processamento de Dados, SERPRO

Introdução: A Assessoria Clínica do Instituto de Tecnologia em Imunobiológicos (Asclin/Bio-Manguinhos/Fiocruz) incorporou no gerenciamento de seus estudos clínicos, novas tecnologias, com softwares que ajudam na tomada de decisão e facilitam a condução de pesquisas clínicas, hoje realizadas de forma descentralizada em vários estados brasileiros. Um dos sistemas é o eCRF (electronic Case Report Form) BioForm, uma ferramenta online que facilita a entrada de informações em um sistema de Banco de Dados.

Objetivo: Além de acelerar o processo de análise estatística dos dados, o sistema permitirá também um gerenciamento mais efetivo dos processos de monitoria e acompanhamento das pesquisas para posterior resolução por parte de investigadores dos estudos clínicos. Como objetivo secundário, está prevista a disponibilização desse sistema para as instituições que fazem parte da Rede Fiocruz de Pesquisa Clínica (RFPC/VPPLR) e da Rede Nacional de Pesquisa Clínica (RNPC/DECIT/MS), o que representará avanços para a pesquisa clínica nacional.

Metodologia: Para a construção desse sistema, firmou-se uma parceria entre Bio-Manguinhos (através da Asclin e da Divisão de Tecnologia da Informação - DITIN) e o Serviço Federal de Processamento de Dados (SERPRO). O desenvolvimento do sistema se deu com a utilização de metodologia ágil. Um aspecto positivo dessa metodologia é o acompanhamento, por parte de Bio-Manguinhos, quase em tempo real. Isto permitiu que alinhamentos fossem feitos ainda durante a construção do sistema, obtendo-se assim uma primeira versão do sistema mais robusta. Outros aspectos do seu desenvolvimento: sistema totalmente em português; segue a documentação regulatória da Anvisa (RDC 17/2010); validação realizada pelo Laboratório de Metrologia e Validação de BioManguinhos (LAMEV); e realização de estudo piloto utilizando duas tecnologias para concluir a validação.

Resultados: O BioForm foi estruturado e construído em módulos: Cadastros básicos e centralizados de profissionais e centros de pesquisa; Inclusão de um estudo clínico e construção de seus respectivos formulários; Randomização (estrutura de blocos, com 
inclusão competitiva e não competitiva); Acompanhamento do preenchimento das fichas clínicas do estudo (execução do estudo); Monitoramento de preenchimento das fichas clínicas; Emissão de Relatórios e Extração do banco de dados para análise estatística.

Conclusão: A primeira versão para uso está prevista para entrar no ar em abril deste ano. Acredita-se que essa ferramenta contribuirá muito com a agilidade, redução de custos e condução de estudos clínicos.

Palavras-Chave: Pesquisa Clínica, eCRF 